\title{
ESTIMATION OF MEASURED DATA OF MICROCHANNEL GAS FLOWS
}

\author{
Jing Fan, Ching Xie, and Jian-Zheng Jiang \\ Institute of Mechanics, Chinese Academy of Sciences, Beijing 100080, China
}

\begin{abstract}
The measured data of mass flow rates and streamwise pressure distributions at various experimental conditions of microchannels carried out by Pong et al (1994), Harley et al (1995), Shih et al (1996), Arkilic et al (1997, 2001), and Zohar et al (2002) are normalized by the kinetic factors $M_{C}$ and $\mathrm{p}_{\mathrm{k}}$, respectively. The normalized data are compared each other, and they are in excellent agreement, except the few with the small differences. This demonstrates that the measured data available are generally accurate.
\end{abstract}

\section{NOMENCLATURE}

$\begin{array}{cl}\text { h } & \text { microchannel height } \\ \text { Kn } & \text { Knudsen number } \\ \mathrm{L} & \text { microchannel length } \\ \dot{\mathrm{M}} & \text { mass flow rate } \\ \dot{\mathrm{M}}_{\mathrm{C}} & \text { normalized factor of mass flow rate } \\ \mathrm{p} & \text { pressure } \\ \mathrm{P} & \text { normalized pressure, } \mathrm{P}=\mathrm{p} / \mathrm{p}_{\mathrm{o}} \\ \mathrm{dp} / \mathrm{dx} & \text { streamwise pressure gradient } \\ \lambda & \text { mean free path } \\ \vartheta & \text { ratio of inlet to outlet pressure, } \vartheta \equiv \mathrm{p}_{\mathrm{i}} / \mathrm{p}_{\mathrm{o}}\end{array}$

Subscripts

i Inlet

o Outlet

\section{INTRODUCTION}

Many experimental studies [1-9] on gas flows through micro-channels were carried out to understand the microscale effects that are important for the design and optimization of MEMS devices. The mass flow rates and streamwise pressure distributions were measured at various conditions as shown in Table 1 . The dimensions were about one micron high by several tens of microns wide and by several thousands microns long. The flow was driven by the pressure differences between the inlet and outlet, with a typical inlet velocity of about 0.2 $\mathrm{m} / \mathrm{s}$ [10]. The flows are two dimensional because of the negligible spanwise effect for the large with-to-height ratio, while the isothermal assumption is valid under the low subsonic conditions without external heating.

Comparing these experimental data each other is helpful to assess their accuracy, and reveal the features of microchannel gas flows. Due to the differences between the experimental conditions, we have to normalize the measured data firstly. Let us image to slice up microchannels a cross section by cross section. Every cross section may be localized as the Poiseuille flow. The mass flow rate may be nicely related to the Knudsen number based on the channel height (see, e.g. Fig.6 in Ref. [11]) when a following normalization factor is used

$$
\dot{\mathrm{M}}_{\mathrm{C}}=\frac{2 \mathrm{~h}^{2}}{\mathrm{v}_{\mathrm{m}}} \frac{\mathrm{dp}}{\mathrm{dx}},
$$

where $h$ is the channel height, $v_{m}=\sqrt{2 R T}$ is the most probable thermal speed, and $\mathrm{dp} / \mathrm{dx}$ is the pressure gradient.

Experiments [1,3,4,9] showed that the streamwise pressure distributions of gas flows through microchannel were nonlinear. This means that $\mathrm{dp} / \mathrm{dx}$ is not constant, which differs from the Poiseuille flow. Therefore, we have to obtain the solution of $\mathrm{dp} / \mathrm{dx}$, before the normalized factor $\mathrm{M}_{\mathrm{p}}$ may be extended to microchannels. 
Table 1. Experimental conditions of microchannel gas flows

\begin{tabular}{|c|c|c|c|c|}
\hline Source & Gas & $\begin{array}{l}\text { Height } \\
(\mu \mathrm{m})\end{array}$ & $\begin{array}{l}\text { Width } \\
(\mu \mathrm{m})\end{array}$ & $\begin{array}{c}\text { Length } \\
(\mu \mathrm{m})\end{array}$ \\
\hline $\begin{array}{c}\text { Pong et al } \\
{[1]}\end{array}$ & $\mathrm{N}_{2}$, He & 1.2 & 40 & 3000 \\
\hline $\begin{array}{l}\text { Harley et al } \\
\text { [2] }\end{array}$ & $\begin{array}{c}\mathrm{N}_{2}, \mathrm{He}, \\
\mathrm{Ar}\end{array}$ & $\begin{array}{l}0.51 \sim \\
19.79\end{array}$ & $\begin{array}{c}100 \sim \\
200\end{array}$ & 10000 \\
\hline $\begin{array}{l}\text { Shih et al } \\
{[3,4]}\end{array}$ & $\mathrm{N}_{2}, \mathrm{He}$ & 1.2 & 40 & 4000 \\
\hline $\begin{array}{l}\text { Arkilic et al } \\
\text { [5-8] }\end{array}$ & $\begin{array}{l}\mathrm{He}, \mathrm{Ar} \\
\mathrm{N}_{2}, \mathrm{CO}_{2}\end{array}$ & 1.33 & 52.3 & 7490 \\
\hline $\begin{array}{c}\text { Zohar et al } \\
\text { [9] }\end{array}$ & $\begin{array}{c}\mathrm{He}, \mathrm{Ar}, \\
\mathrm{N}_{2}\end{array}$ & $\begin{array}{c}0.53 \sim \\
0.97\end{array}$ & 40 & 4000 \\
\hline
\end{tabular}

\section{CONSERVATION OF MASS FLOW RATE THROUGH MICROCHANNELS}

Consider a cross section of microchannel. The mass flow rate through it may be written as

$$
\dot{\mathrm{M}} / \dot{\mathrm{M}}_{\mathrm{N}-\mathrm{S}}=\phi(\mathrm{Kn}),
$$

with

$$
\dot{M}_{N-S}=\frac{2 h^{3}}{3 \mu R T} p \frac{d p}{d x},
$$

is the non-slip Navier-Stokes solution of mass flow rate for the Poiseuille flows, and with

$$
\phi(\mathrm{Kn}) \cong 1+6 \alpha \mathrm{Kn}+\frac{12}{\pi} \mathrm{Kn} \ln (1+\beta \mathrm{Kn}),
$$

where $\alpha=1.318889, \beta=0.387361$. $\phi(\mathrm{Kn})$ reflects the local deviation from the $\mathrm{N}-\mathrm{S}$ solution owing to the microscale effect. Eq. (4) is fitted based on the numerical solution of the linearized Boltzmann equation [12,13], under the tangential momentum accommodation coefficient $\sigma=1$.

The mass flow rate conservation through microchannels requires

$$
\frac{\mathrm{d} \dot{\mathrm{M}}}{\mathrm{dx}}=0 .
$$

Substituting Eq. (2) into (5) and eliminating the constant term $2 \mathrm{~h}^{3} /(3 \mu \mathrm{RT})$ give rise to a simple relation between $\mathrm{p}$ and $\mathrm{Kn}$

$$
\frac{\mathrm{d}}{\mathrm{dx}}\left\{\left[1+6 \alpha \mathrm{Kn}+\frac{12}{\pi} \mathrm{Kn} \ln (1+\beta \mathrm{Kn})\right] \mathrm{p} \frac{\mathrm{dp}}{\mathrm{dx}}\right\}=0,
$$

or

$$
\left[1+6 \alpha \mathrm{Kn}+\frac{12}{\pi} \mathrm{Kn} \log (1+\beta \mathrm{Kn})\right] \mathrm{P} \frac{\mathrm{dP}}{\mathrm{dX}}=\mathrm{C},
$$

where $\mathrm{C}$ is a constant undetermined, $\mathrm{P}=\mathrm{p} / \mathrm{P}_{\mathrm{o}}, \mathrm{X}=\mathrm{x} / \mathrm{L}$, $\mathrm{p}_{0}$ is the outlet pressure, and $\mathrm{L}$ is the microchannel length.

Eq. (6) may be regarded alternatively as a special case of the generalized Reynolds equation with the bearing number $\Lambda=0$. The generalized Reynolds equation was firstly derived by Fukui and Kaneko [14] from the linearized Boltzmann equation, and it works quite well for air slider bearings. Recently C. Shen [15] suggested to apply it to microchannels. Eq. (6) is valid over the entire flow regime from continuum to free molecular, because its kernel $\phi(\mathrm{Kn})$ is obtained based on the linearized Boltzmann equation.

\section{NORMALIZED FACTORS OF PRESSURE AND MASS \\ FLOW RATE}

For hard-sphere molecules, the mean free path $\lambda=\mathrm{kT} / \sqrt{2} \sigma_{\mathrm{T}} \mathrm{p}$, where the collision cross section $\sigma_{\mathrm{T}}$ is constant. Consequently, the Knudsen number along a microchannel may be expressed as follows

$$
\mathrm{Kn} \equiv \frac{\lambda}{\mathrm{h}}=\frac{\lambda_{\mathrm{o}}}{\mathrm{h}} \cdot \frac{\lambda}{\lambda_{\mathrm{o}}}=\frac{\mathrm{Kn}_{\mathrm{O}}}{\mathrm{P}},
$$

where the subscript o denotes the outlet.

Substitution of Eq. (8) into (7) yields

$\left[\mathrm{P}+6 \alpha \mathrm{Kn}_{\mathrm{o}}+\frac{12 \mathrm{Kn}_{\mathrm{O}}}{\pi} \log \left(1+\beta \mathrm{Kn}_{\mathrm{o}} / \mathrm{P}\right)\right] \mathrm{dP}=\mathrm{CdX}$,

Integrating Eq. (9) from the inlet $\mathrm{X}=0$ and $\mathrm{P}=\vartheta \equiv \mathrm{p}_{\mathrm{i}} / \mathrm{p}_{\mathrm{o}}$, we have

$$
\begin{aligned}
& \frac{1}{2} \mathrm{P}^{2}+6 \alpha \mathrm{Kn}_{\mathrm{O}} \mathrm{P}+\frac{12 \mathrm{Kn}_{\mathrm{o}}}{\pi}\left[\mathrm{P} \ln \left(1+\frac{\beta \mathrm{Kn}_{\mathrm{o}}}{\mathrm{P}}\right)+\beta \mathrm{Kn}_{\mathrm{o}} .\right. \\
& \left.\ln \left(\mathrm{P}+\beta \mathrm{Kn}_{\mathrm{o}}\right)\right]-\frac{1}{2} \vartheta^{2}-6 \alpha \mathrm{Kn}_{\mathrm{o}} \vartheta+\frac{12 \mathrm{Kn}_{\mathrm{O}}}{\pi} . \\
& {\left[\vartheta \ln \left(1+\beta \mathrm{Kn}_{\mathrm{o}} / \vartheta\right)+\beta \mathrm{Kn}_{\mathrm{o}} \ln \left(\vartheta+\beta \mathrm{Kn}_{\mathrm{o}}\right)\right]=\mathrm{CX}}
\end{aligned}
$$

At the outlet $\mathrm{X}=1, \mathrm{P}=1$, therefore

$$
\begin{aligned}
& C=\frac{1}{2}\left(1-\vartheta^{2}\right)+6 \alpha \mathrm{Kn}_{\mathrm{o}}(1-\vartheta)+\frac{12 \mathrm{Kn}_{\mathrm{o}}}{\pi} . \\
& {\left[\ln \left(1+\beta \mathrm{Kn}_{\mathrm{o}}\right)+\beta \mathrm{Kn}_{\mathrm{o}} \ln \left(1+\beta \mathrm{Kn}_{\mathrm{o}}\right) \quad\right. \text {. }} \\
& \left.-\vartheta \ln \left(1+\beta \mathrm{Kn}_{\mathrm{o}} / \vartheta\right)-\beta \mathrm{Kn}_{\mathrm{o}} \ln \left(\vartheta+\beta \mathrm{Kn}_{\mathrm{o}}\right)\right]
\end{aligned}
$$

The normalized factor of mass flow rate Mc through microchannels may be obtained using Eqs. (1), (7) and (11)

$$
\dot{\mathrm{M}}_{\mathrm{c}}=\left.\frac{2 \mathrm{~h}^{2}}{\mathrm{v}_{\mathrm{m}}} \cdot \frac{\mathrm{dp}}{\mathrm{dx}}\right|_{\mathrm{i}}=\frac{2 \mathrm{~h}^{2}}{\mathrm{v}_{\mathrm{m}}} \cdot \frac{\mathrm{Cp}_{\mathrm{o}}^{2}}{\phi\left(\mathrm{Kn}_{\mathrm{i}}\right) \mathrm{p}_{\mathrm{i}} \mathrm{L}},
$$

where the subscript I denotes the inlet.

The kinetic solution of the streamwise pressure distribution $\mathrm{p}_{\mathrm{k}}$ may be numerically solved from Eq. (10) that depends upon the parameters $\vartheta$ and $\mathrm{Kn}_{\mathrm{O}}$.

\section{COMPARISON OF NORMALIZED MEASURED MASS FLOW RATES AND STREAMWISE PRESSURE DISTRIBUTIONS}

Figure 1 compares the normalized mass flow rates at different conditions carried out by Harley et al [2], Shih et al 
[4], Arkilic et al [6-8], and Zohar et al [9], respectively. Generally they agree well each other, whereas the small differences between the helium cases of Shih et al [4] and Arkilic et al [6,7] are observed. A relation of the normalized mass flow rate to the inlet $\mathrm{Kn}_{\mathrm{i}}$ may be simply fitted as

$\dot{\mathrm{M}}=\dot{\mathrm{M}}_{\mathrm{c}} /\left(\mathrm{a}+\mathrm{bKn}_{\mathrm{i}}+\mathrm{cKn} n_{\mathrm{i}}^{2}+\mathrm{dKn}_{\mathrm{i}}^{3}+\mathrm{eKn}_{\mathrm{i}}^{4}\right)$,

with $a=0.021998, b=12.48288, c=-87.95779, d=397.432$, and $\mathrm{e}=-716.724$.

Figure 2 and Table 2 show the ratio of the measured pressure distributions to the kinetic solution $\mathrm{p}_{\mathrm{k}}$. Cases A1-A5 correspond to the inlet pressure of 25, 20, 15, 10 and 5 psig, respectively, for nitrogen at the experimental conditions of Pong et al [1]; cases B1-B3 to the inlet pressure of 19, 13.6 and 8.7 psig, respectively, for helium at the experimental conditions of Shih et al [4]; cases C1-C3 to the inlet pressure of 2.1, 2.8 and 3.4atm for nitrogen, while cases D1-D4 to 1.9, 2.6, 3.3 and 4atm for argon, respectively, at the experimental conditions of Zohar et al [9]. The four series of cases have the same outlet pressure of $1 \mathrm{~atm}$, but the different inlet pressures and channel heights. The comparison is very satisfactory. All the values are close to unity, and the differences are within 5\%, except three measured points (case A4: $\mathrm{x}=1800 \mu \mathrm{m}, \mathrm{P}_{\exp } / \mathrm{p}_{\mathrm{k}}=0.907$; case B1: $\mathrm{x}=3300 \mu \mathrm{m}, \mathrm{P}_{\exp } / \mathrm{p}_{\mathrm{k}}=1.054$; case D4: $\mathrm{x}=3300 \mu \mathrm{m}$, $\left.\mathrm{P}_{\exp } / \mathrm{p}_{\mathrm{k}}=1.092\right)$.

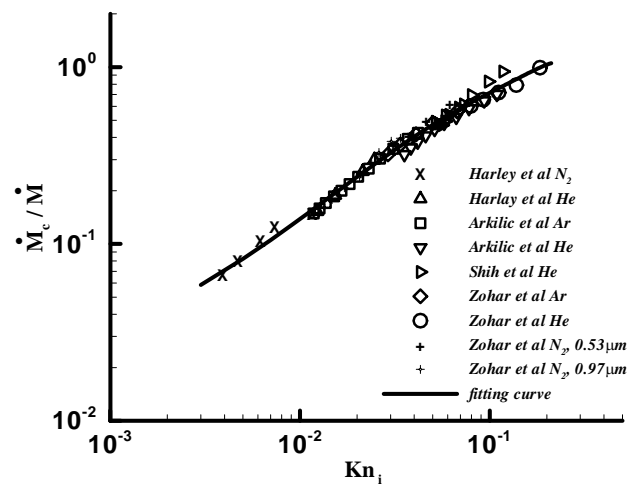

Figure 1. Comparison of normalized measured mass flow rates through microchannels versus the inlet Knudsen number.

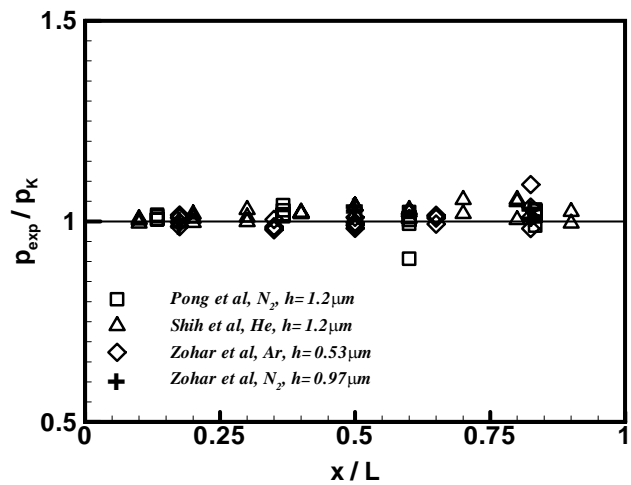

Figure 2. Comparison of normalized measured streamwise pressure distributions.

Table 2. The values of $\mathrm{p}_{\exp } / \mathrm{p}_{\mathrm{k}}$ at different conditions.

\begin{tabular}{|c|c|c|c|}
\hline Case & $x(\mu \mathrm{m})$ & $\mathrm{p}_{\mathrm{i}}$ (psig) & $\mathrm{p}_{\exp } / \mathrm{p}_{\mathrm{k}}$ \\
\hline \multirow[t]{4}{*}{ A1 } & 400 & 25 & 1.013 \\
\hline & 1100 & 25 & 1.015 \\
\hline & 1800 & 25 & 0.994 \\
\hline & 2500 & 25 & 0.989 \\
\hline \multirow[t]{4}{*}{$\mathrm{A} 2$} & 400 & 20 & 1.005 \\
\hline & 1100 & 20 & 1.018 \\
\hline & 1800 & 20 & 1.010 \\
\hline & 2500 & 20 & 1.013 \\
\hline \multirow[t]{4}{*}{ A3 } & 400 & 15 & 1.005 \\
\hline & 1100 & 15 & 1.028 \\
\hline & 1800 & 15 & 1.004 \\
\hline & 2500 & 15 & 1.013 \\
\hline \multirow[t]{4}{*}{$\mathrm{A} 4$} & 400 & 10 & 1.006 \\
\hline & 1100 & 10 & 1.012 \\
\hline & 1800 & 10 & 0.907 \\
\hline & 2500 & 10 & 1.030 \\
\hline \multirow[t]{4}{*}{ A5 } & 400 & 5 & 1.017 \\
\hline & 1100 & 5 & 1.041 \\
\hline & 1800 & 5 & 1.024 \\
\hline & 2500 & 5 & 1.027 \\
\hline \multirow[t]{8}{*}{ B1 } & 400 & 19 & 1.006 \\
\hline & 800 & 19 & 1.018 \\
\hline & 1200 & 19 & 1.029 \\
\hline & 1600 & 19 & 1.022 \\
\hline & 2000 & 19 & 1.038 \\
\hline & 2400 & 19 & 1.029 \\
\hline & 3200 & 19 & 1.054 \\
\hline & 3600 & 19 & 1.024 \\
\hline \multirow[t]{8}{*}{ B2 } & 400 & 13.6 & 1.003 \\
\hline & 800 & 13.6 & 1.008 \\
\hline & 1200 & 13.6 & 1.011 \\
\hline & 1600 & 13.6 & 1.021 \\
\hline & 2000 & 13.6 & 1.038 \\
\hline & 2400 & 13.6 & 1.023 \\
\hline & 2800 & 13.6 & 1.054 \\
\hline & 3200 & 13.6 & 1.049 \\
\hline \multirow[t]{5}{*}{ B3 } & 400 & 8.7 & 0.997 \\
\hline & 800 & 8.7 & 0.997 \\
\hline & 1200 & 8.7 & 0.999 \\
\hline & 1600 & 8.7 & 1.019 \\
\hline & 2000 & 8.7 & 1.018 \\
\hline
\end{tabular}




\begin{tabular}{|c|c|c|c|}
\hline & 2400 & 8.7 & 1.007 \\
\hline & 2800 & 8.7 & 1.019 \\
\hline & 3200 & 8.7 & 1.004 \\
\hline & 3600 & 8.7 & 0.995 \\
\hline \multirow[t]{3}{*}{ C1 } & 700 & 16.1 & 1.004 \\
\hline & 2000 & 16.1 & 1.045 \\
\hline & 3300 & 16.1 & 1.039 \\
\hline \multirow[t]{3}{*}{ C2 } & 700 & 26.4 & 0.992 \\
\hline & 2000 & 26.4 & 1.044 \\
\hline & 3300 & 26.4 & 1.014 \\
\hline \multirow[t]{3}{*}{ C3 } & 700 & 35.2 & 1.011 \\
\hline & 2000 & 35.2 & 1.032 \\
\hline & 3300 & 35.2 & 1.036 \\
\hline \multirow[t]{5}{*}{ D1 } & 700 & 13.2 & 1.016 \\
\hline & 1400 & 13.2 & 1.005 \\
\hline & 2000 & 13.2 & 0.991 \\
\hline & 2600 & 13.2 & 0.993 \\
\hline & 3300 & 13.2 & 0.982 \\
\hline \multirow[t]{5}{*}{ D2 } & 700 & 23.4 & 1.009 \\
\hline & 1400 & 23.4 & 0.979 \\
\hline & 2000 & 23.4 & 0.997 \\
\hline & 2600 & 23.4 & 1.015 \\
\hline & 3300 & 23.4 & 1.035 \\
\hline \multirow[t]{5}{*}{ D3 } & 700 & 33.7 & 0.987 \\
\hline & 1400 & 33.7 & 0.987 \\
\hline & 2000 & 33.7 & 0.983 \\
\hline & 2600 & 33.7 & 1.008 \\
\hline & 3300 & 33.7 & 1.010 \\
\hline \multirow[t]{5}{*}{ D4 } & 700 & 44.0 & 0.998 \\
\hline & 1400 & 44.0 & 0.983 \\
\hline & 2000 & 44.0 & 1.010 \\
\hline & 2600 & 44.0 & 1.012 \\
\hline & 3300 & 44.0 & 1.092 \\
\hline
\end{tabular}

\section{CONCLUSIONS}

The measured data of mass flow rates and streamwise pressure distributions through microchannels at various experimental conditions are normalized by the kinetic factors

$\mathrm{M}_{\mathrm{C}}$ and $\mathrm{p}_{\mathrm{k}}$, respectively. The normalized comparison is satisfactory, except the few that show the small differences. This demonstrates that the measured data available are generally accurate. Consequently, the fitting formula of the measured mass flow rates and the kinetic solution of streamwise pressure distribution may be reliably applied to the design and optimization of MEMS devices.

\section{ACKNOWLEDGMENTS}

This work is supported by the National Natural Science Foundation of China under grants 90205024 and 10425211.

\section{REFERENCES}

1. K. C. Pong, C. M. Ho, J. Q. Liu, and Y. C. Tai. Non-linear pressure distribution in uniform micro-channels. ASMEFED, 197, 51 (1994)

2. J. C. Harley, Y. Huang, H. Bau, and J. N. Zemel. Gas flow in micro-channels. J. Fluid Mech. 248, 257 (1995)

3. J. C. Shih, C. M. Ho, J. Liu, and Y. C. Tai. Non-linear pressure distribution in uniform microchannels. ASMEAMD, 238 (1995)

4. J. C. Shih, C. M. Ho, J. Q. Liu, and Y. C. Tai. Monatomic and polyatomic gas flow through uniform microchannels. ASME-DSC, 59, 197 (1996)

5. E. B. Arkilic, K. Breuer, and M. A. Schmidt. Gaseous slip flow in long micro-channels. J. MicroElectroMechanical Systems, 6, 167 (1997)

6. E. B. Arkilic, M. A. Schmidt, and K. S. Breuer. Measurement of the TMAC in silicon microchannels. in Rarefied Gas Dynamics, edited by C. Shen, Peking University Press, p. 983 (1997)

7. E. B. Arkilic. Measurement of the mass flow and tangential momentum accommodation coefficient in silicon microchannels, Ph.D. thesis, MIT, FDRL TR 97-1 (1997)

8. E. B. Arkilic, K. S. Breuer and M. A. Schmidt. Mass flow and tangential momentum accommodation in silicon micromachined channels. J. Fluid Mech., 437, 29 (2001)

9. Y. Zohar, S. Y. K. Lee, W. Y. Lee, L. Jiang and P. Tong. Subsonic gas flow in a straight and uniform microchannel. $J$. Fluid Mech., 472, 257 (2002)

10. C. M. Ho and C. Y. Tai. Micro-electro-mechanical-systems (MEMS) and fluid flows. Annu. Rev. Fluid Mech., 30, 579 (1998).

11. J. Fan, and C. Shen, Statistical simulation of low-speed rarefied gas. J. Comp. Phys., 167, 393 (2001)

12. F. J. Alexander, A. L. Garcia, and B. J. Alder. Direct simulation Monte Carlo for thin-film bearings. Phys. Fluids, 6, 3854 (1994)

13. S. Fukui, and R. Kaneko, A database for interpolation of Poiseuille flow rates for high Knudsen number lubrication problem. J. Tribology, 112, 78 (1990)

14. S. Fukui, and R. Kaneko. Analysis of ultrathin gas film lubrication based on linearized Boltzmann equation: First report derivation of a generalized lubrication equation including thermal creep flow. J. Tribology, 110, 253 (1988)

15. C. Shen. A strict kinetic solution of the finite length microchannel flow. to appear in the 3rd International Conference on Microchannels and Minichannels, June 1315, 2005, Toronto, Ontario, Canada 